\author{
Marquette University \\ e-Publications@Marquette
}

Social and Cultural Sciences Faculty Research and Publications

$8-2020$

\title{
The Neighborhood-Level Association Between Alcohol Outlet Density and Female Criminal Victimization Rates
}

\author{
Aleksandra J. Snowden \\ Marquette University, aleksandra.snowden@marqutte.edu \\ Sara Hockin \\ Georgia State University \\ William Alex Pridemore \\ State University of New York - Albany
}

Follow this and additional works at: https://epublications.marquette.edu/socs_fac

Part of the Social and Behavioral Sciences Commons

\section{Recommended Citation}

Snowden, Aleksandra J.; Hockin, Sara; and Pridemore, William Alex, "The Neighborhood-Level Association Between Alcohol Outlet Density and Female Criminal Victimization Rates" (2020). Social and Cultural Sciences Faculty Research and Publications. 256.

https://epublications.marquette.edu/socs_fac/256 
Marquette University

\section{e-Publications@Marquette}

\section{Sociology Faculty Research and Publications/College of Arts and Sciences}

This paper is NOT THE PUBLISHED VERSION; but the author's final, peer-reviewed manuscript. The published version may be accessed by following the link in the citation below.

Journal of Interpersonal Violence, (2017): 1-24. DOI. This article is CSAGE Publications and permission has been granted for this version to appear in e-Publications@Marquette. SAGE Publications does not grant permission for this article to be further copied/distributed or hosted elsewhere without the express permission from SAGE Publications.

\section{The Neighborhood-Level Association Between Alcohol Outlet Density and Female Criminal Victimization Rates}

Aleksandra J. Snowden

Marquette University, Milwaukee, WI, USA

Sara Hockin

Georgia State University, Atlanta, GA, USA

William Alex Pridemore

University at Albany, State University of New York, Albany, NY, USA

\section{Abstract}

The aim of this study was to explore the neighborhood-level association between alcohol outlet density and non-intimate partner violent victimization rates among females. Violent offending and victimization are more prevalent for males than females, and most research on alcohol outlets and violence emphasizes males. Studies that do focus on alcohol outlets and female violent victimization tend to focus on intimate partner violence (IPV), yet non-IPV events are over three quarters of all female violent victimization incidents in the United States. We collected data on violent victimization rates, on- and off-premise alcohol outlet density, and neighborhood-level covariates of violence rates for Milwaukee block groups. We used spatially lagged regression 
models to test this association, to compare non-IPV results with those for overall female violent victimization rates, and to compare results for females with those for males. Our findings showed density of both on- and offpremise alcohol outlets was positively associated with non-IPV female violent victimization rates, which is an important finding given lack of research on this topic. We also found results for females (both overall and nonIPV violent victimization) were generally the same as for males, but the effect of off-premise outlets on non-IPV female violent victimization rates was weaker than the same association for males. Our findings have clear policy implications for local jurisdictions. Alcohol outlet density is important for both female and male violent victimization. Limiting the licensing of alcohol-selling establishments, especially those that engage in irresponsible retail practices, may be a suitable approach to address violent victimization.

\section{Keywords}

alcohol and drugs, community violence, criminology, violence

\section{Introduction}

There is substantial evidence from multiple disciplines of an ecological association between alcohol outlets $\frac{1}{}$ and violent crimes (Snowden, 2015). Alcohol outlets are associated with homicides (Scribner, Cohen, Kaplan, \& Allen, 1999), simple and aggravated assaults (Pridemore \& Grubesic, 2013; Snowden \& Pridemore, 2013), and other types of violent crime like robbery and domestic violence (Livingston, 2011; Scribner, MacKinnon, \& Dwyer, 1995; Snowden, 2016a; Snowden \& Freiburger, 2015; Zhu, Gorman, \& Horel, 2004). Less is known about the role alcohol outlets play in female victimization. With the exception of a few studies of the effects of outlets on gender-specific intimate partner violence (IPV; for example, Waller et al., 2012) and on rape and domestic violence (e.g., Livingston, 2011), most prior studies examined overall rather than gender-specific violence. This is important because there are theoretical reasons to believe that relative to male victimization rates, female victimization rates may have unique covariates or may covary with predictors at greater or lesser strength (Heise, 1998; O'Keefe \& Treister, 1998). In addition, research on female victimization typically focuses on IPV, which is a serious but less frequent type of victimization. Therefore, the goal of this study was to examine the impact of alcohol outlet density on overall (including IPV victimization) and on non-IPV female victimization rates. The latter is novel to the literature.

Our study makes several important contributions to the literature on alcohol outlets and violence. First, we focus on overall female victimization, which includes but is not limited to IPV. Second, we examine female nonIPV victimization, which is $81 \%$ of total female violent victimization (Truman \& Langton, 2015). Third, we use census block groups as units of analysis, which are generally accepted proxies for neighborhoods, and estimate spatially informed regression models to control for spatial dependence in our spatially referenced data. Last, we compare the effects of alcohol outlets on victimization across genders to better understand if any associations are unique to females or are simply reflecting larger patterns of association.

\section{Literature Review}

\section{Alcohol Availability}

Alcohol availability theory suggests an association between alcohol outlet density and female victimization rates because without availability there can be no alcohol use or associated problems (Birckmayer, Holder, Yacoubian, \& Friend, 2004; Livingston, Chikritzhs, \& Room, 2007; Stockwell \& Gruenewald, 2001). In general, when alcohol availability increases and becomes readily available through retail outlets, it triggers a range of changes, including (a) greater accessibility and lowered distance to travel to the nearby alcohol outlet to purchase alcohol, (b) increased market competition resulting in lower priced alcohol products, (c) increased exposure to marketing materials that promote alcohol purchase and consumption, and (d) eventual change in the social norms that govern frequency and volume of alcohol consumed by individuals (Birckmayer et al., 2004; Campbell et al., 2009). Thus, greater alcohol consumption is expected in areas with high alcohol availability (i.e., retail 
establishments that sell alcoholic beverages) relative to areas with lower alcohol availability (Douglass, Wagenaar, \& Barkey, 1980; Rowland et al., 2014).

Consideration of alcohol availability in the context of violence is important because alcohol is no ordinary commodity (Babor et al., 2010). The physiological effects of alcohol lower inhibitions, slow cognitive and physical reactions, make people less fully aware of dangerous situational factors, and reduce ability to engage in avoidance behaviors or other defensive actions when confronted with a serious situation (Buddie \& Parks, 2003; Room, Babor, \& Rehm, 2005; Testa \& Parks, 1996). Alcohol consumption at public venues may result in disinhibited decision-making process (e.g., leaving the guarded premise with a stranger) that may increase one's risk of victimization (Buddie \& Parks, 2003; Cohen \& Felson, 1979).

Alcohol availability can be reduced via policy levers, and prior studies suggest reducing alcohol availability can have positive social effects (e.g., Pridemore \& Snowden, 2009), but less is known about how alcohol availability influences female-specific victimization. Duailibi et al. (2007) examined both overall (non-gender-specific) homicide and female-specific assaults before and after a restrictive alcohol policy that regulated on-premise alcohol sales, finding a significant decrease in all homicides but a nonsignificant decrease in violence against women following the implementation of the restrictive alcohol availability policy. These findings, together with the more general dearth of studies, point to the lack of information on the relationship between alcohol availability and female victimization. Our study will help to fill this gap.

\section{Routine Activities and Outlet Characteristics}

Routine activities theory (Cohen \& Felson, 1979) presents reasons for an association between alcohol outlet density and female victimization. According to the theory, crime is a result of convergence in time and space of three elements: a motivated offender, a suitable target, and a lack of capable guardian (Cohen \& Felson, 1979). Opportunities for victimization vary across geographic areas depending on the types of places conducive for convergence in time and space of three elements operating in those areas (Sampson \& Wooldredge, 1987). For example, on-premise alcohol outlets may create optimal conditions for victimization by providing a flow of intoxicated suitable targets for victimization who are unguarded once they leave the relatively protective nature of these premises. Bars or clubs draw high-risk patrons who become suitable targets for victimization (Livingston et al., 2007) when alone and intoxicated (Homel \& Clark, 1994). They also tend to be located in retail areas with less guardianship from nearby residents (Gruenewald, Freisthler, Remer, LaScala, \& Treno, 2006), so when other businesses have closed late at night, local residents are not outside to protect patrons who leave the premises. On the contrary, on-premise outlet employees such as bouncers, security personnel, or waitstaff can serve as capable guardians and their absence can create opportunities for victimization (Cohen \& Felson, 1979). Some bars or clubs may have permissive attitudes toward violence and patrons are attracted to outlets where they believe their behavior will "fit" with the environment, so aggressive individuals (i.e., motivated offenders) are likely to concentrate in such outlets (Leather \& Lawrence, 1995). The permissive attitudes about violence may also be affected by bar or club employees' biased views against women drinking in bars and talking to strangers (Buddie \& Parks, 2003) and may reduce the likelihood of intervention by employees. Outlets that serve intoxicated patrons, offer discounted drinks, and permit overcrowding increase the risk of assaults occurring there (Stockwell, Lang, \& Rydon, 1993), and bars or pubs that serve young patrons have greater levels of female victimization (Buddie \& Parks, 2003).

Off-premise alcohol outlets also may create opportunities for victimization by providing intoxicating beverages consumed in the context of less protected settings relative to guardianship levels in on-premise outlets (Stockwell et al., 1993). A recent study found off-premise alcohol outlet density was positively associated with IPV rates, though on-premise outlet density had no association (Snowden, 2016a). Livingston (2011), however, found on-premise outlets had a positive association while off-premise outlets had a stronger and negative association with domestic violence, though Snowden's (2016a) and Livingston's (2011) conclusions may be due to methodological differences in the two studies. In any event, availability of alcohol outlets may influence 
routine activities related to where alcohol is consumed and consequently where violence takes place (Stockwell et al., 1993). For example, in an area with greater concentration of outlets selling packaged liquor, drinking may occur in places typically out of the public eye and where norms and expectations about violence may not be strictly enforced (Stockwell et al., 1993). In addition, a greater concentration of off-premise outlets may encourage heavier consumption relative to on-premise outlets due to the price differences per alcohol beverage unit (Halonen et al., 2013).

Finally, alcohol outlets may promote heavy alcohol use among couples already at risk for IPV offending and victimization (Cunradi, 2007; Cunradi, Caetano, Clark, \& Schafer, 2000) and provide places "where groups of persons at risk for IPV may form and mutually reinforce IPV-related attitudes, norms, and problem behaviors" (Cunradi, 2010, p. 799), both of which highlight the importance of the role that alcohol availability plays in female victimization.

\section{Social Disorganization}

Any association between alcohol outlet density and violence may also be explained by social disorganization theory, which argues areas characterized by poverty, rapid population growth, ethnic/racial heterogeneity, and transiency are the same areas where high levels of crime occur (Shaw \& McKay, 1942). This classical criminological theory was underutilized in the 1960s and 1970s when individual-level explanations dominated the field. In the late 1980s and 1990s, the social disorganization theory was revitalized by the Project on Human Development in Chicago Neighborhoods (PHDCN), which examined Chicago's social, economic, political, and structural changes to explain Chicago crime patterns (Sampson, Raudenbush, \& Earls, 1997). The PHDCN provided rich neighborhood-level data for a careful assessment of the role that neighborhood characteristics play in crime, resulting in further elaborations of social disorganization theory (Sampson et al., 1997).

Contemporary elaborations of the social disorganization theory propose the importance of collective efficacy for crime control, and that crime rates are higher in communities that are unable to exert informal social control to limit available criminal opportunities (Bursik, 1988; Sampson \& Groves, 1989; Shaw \& McKay, 1942).

Communities low in collective efficacy cannot organize as a group to solve commonly identified problems and therefore have high crime rates (Sampson et al., 1997). Snowden (2016b) found social disorganization in neighborhoods was positively associated with total, on-, and off-premise alcohol outlet density, suggesting socially disorganized communities also may be unable to control the opening of alcohol outlets in their neighborhoods or exert valuable influence over alcohol outlet managers or owners (Pridemore \& Grubesic, 2012).

Social disorganization could also matter because of its relationship with neighborhood rates of violence. Benson, Fox, DeMaris, and Van Wyk (2003) studied the association between social disorganization and IPV. They found a stronger relationship in the most disadvantaged neighborhoods, suggesting a concentration of alcohol outlets in such neighborhoods results in greater harm than in socially organized neighborhoods. Disorganized neighborhoods, which may also be neighborhoods with higher concentration of alcohol outlets (Nielsen, Hill, French, \& Hernandez, 2010; Snowden, 2016b), create cognitive landscapes that promote increased alcohol consumption and changes in norms around aggressive behaviors (Cunradi, 2009). These neighborhoods also tend to have other characteristics associated with IPV (e.g., unemployment and poverty) that add to the impact of outlets (Cunradi, Mair, Ponicki, \& Remer, 2011) so the effect of outlet density on violence may be stronger in disorganized neighborhoods (Pridemore \& Grubesic, 2012). This interaction effect may occur because disorganized neighborhoods have fewer sources of support for residents experiencing conflict, and norms about intolerance for IPV are not as salient in neighborhoods with low collective efficacy (Browning, 2002). In addition, off-premise outlets in socially disorganized neighborhoods are more likely to provide large single bottles of refrigerated drinks marketed for immediate consumption (Cunradi, 2010) that may influence the amount of alcohol consumed in private settings. 
Research focusing on how social disorganization impacts non-IPV female victimization is limited, but the mechanisms suggested by Cunradi (2009) and Benson et al. (2003) in relation to IPV may also apply to non-IPV female victimization. Socially disorganized neighborhoods may create more opportunities for violence by providing alcohol-selling establishments that encourage increased alcohol consumption, where norms about consumption and intolerance of IPV encourage such outcomes (Cunradi, 2009). In addition, due to high transiency in socially disorganized neighborhoods, neighbors may be less likely to know each other or less likely to intervene in events occurring in their neighborhoods (Shaw \& McKay, 1942). Areas with high outlet density also may create additional flow from nonresidents who likely have little interest in utilizing informal control and serving as capable guardians over events in the area (Sampson, 1986).

\section{Hypotheses}

Given this review of the literature, we tested two main hypotheses:

Hypothesis 1: Alcohol outlet density is positively associated with overall female violent victimization rates.

Hypothesis 2: Alcohol outlet density is positively associated with non-IPV female violent victimization rates.

We also carried out further exploratory analyses. While theory and prior research are not strong enough to suggest which may have stronger effects, we tested for differential effects of on- and off-premise alcohol outlet density on overall and non-IPV female violent victimization rates. Finally, to determine whether any effects of on- and off-premise alcohol outlet density on female victimization rates are unique to females or are simply reflecting a more general impact on community violence rates, we tested for effects of alcohol outlet density on male violent victimization rates.

\section{Data and Method}

\section{Research Site and Units of Analysis}

Milwaukee, Wisconsin, was the research site for this study. Milwaukee is the largest city in Wisconsin, covering 96 square miles (U.S. Census Bureau, 2014). Its population of almost 600,000 is ethnically diverse: $40 \%$ African American, $37 \%$ non-Hispanic or Latino White, $17 \%$ Hispanic or Latino, and 3.5\% Asian (U.S. Census Bureau, 2014).

Census block groups within the city of Milwaukee were our units of analysis. We used block groups because they are the smallest and most ecologically meaningful administrative units for approximating neighborhoods. Sampson and Raudenbush (2004) and Grannis (1998) showed block groups adequately reflect the layout of neighborhoods. Moreover, Parker and Wolz (1979) argued alcohol outlet density is related to locations small enough to be influenced by varying population structure and geographical stratification (Britt, Carlin, Toomey, \& Wagenaar, 2005). This is important because using larger units (e.g., zip codes, cities, states) may obscure the fundamental nature of outlet density (Parker \& Wolz, 1979) and increase the likelihood of aggregation bias.

\section{Dependent Variables}

The Milwaukee Police Department provided us with individual-level criminal incident data from January 2013 until December 2014. Data included incident number, district number, incident date, National Incident-Based Reporting System (NIBRS) offense code, NIBRS offense code description, crime category (i.e., violent, property, or other), offense sequence number, personal record number, person involvement (i.e., arrested, suspect, or victim), victim sex, if it was a domestic violence incident (i.e., yes, no, or null), incident address, and location type.

We used these data to create four dependent variables: (a) overall female violent victimization, (b) female nonIPV violent victimization, (c) overall male violent victimization, and (d) male non-IPV violent victimization. Violent 
victimization included aggravated assault, nonnegligent murder, and robbery. We classified non-IPV violent victimization as the crimes in which the victim was not victimized in the course of a domestic violence incident. These incidents were geocoded using the City of Milwaukee geolocator and resulted in over $99 \%$ successful match for each of these variables. The data were subsequently aggregated to census block groups using data on spatial location. These raw counts were standardized by census block group land area. Finally, we took the square root of the rates per square mile to address skewed distributions (and this transformation worked better than using a log base 10 function).

\section{Main Independent Variables}

Wisconsin Department of Revenue provided us with data on active alcohol outlet licenses for fiscal year 2013/2014. These data included license address, which we geocoded using the City of Milwaukee geolocator with a $99.7 \%$ successful match. We queried the data for alcohol outlet type, which allowed us to disaggregate into on- and off-premise alcohol outlets. We aggregated these data to census block groups based on spatial location and we divided these raw counts by census block group land area to create density per square mile. We corrected for skewed distributions of each of these densities using a log base 10 function (which resulted in the most acceptable reduction of the skewness value relative to alternative transformations).

\section{Control Variables}

We obtained socioeconomic data from the 2013 U.S. Census Bureau American Community Survey 5-year estimate database. We followed the social disorganization framework (Sampson et al., 1997) and created four scales to capture social disorganization, including (a) Concentrated Affluence, (b) Concentrated Disadvantage, (c) Cultural Heterogeneity, and (d) Residential Stability. The first scale, Concentrated Affluence $(\alpha=.85)$, consisted of percent of adults with college education or beyond, percent of professionals and managers among those in the civilian labor force, and percent of families with incomes $>$ US\$75,000. The second scale, Concentrated Disadvantage $(\alpha=.62)$, included percent African American, percent of households on public assistance, percent unemployed, and percent living below poverty line. The third scale, Cultural Heterogeneity $(\alpha=.75)$, was comprised of percent Hispanic or Latino and percent foreign-born. The last scale, Residential Stability $(\alpha=.67)$, included percent living in the same house 1 year prior and percent owner-occupied housing units. The distributions of these factors were skewed and we transformed them using log base 10 function (which resulted in the most acceptable reduction of the skewness values).

Following routine activities theory (Cohen \& Felson, 1979) and in line with prior work in this area (e.g., Freisthler, Midanik, \& Gruenewald, 2004), we controlled for population density and percent vacant housing units to account for greater availability of vulnerable victims in block groups where population density is higher and reduced guardianship where percent vacant housing units is higher. The data were skewed and we transformed them using a square root function that yielded the most appropriate reduction in the skewness values.

\section{Analytic Strategy}

We used IBM SPSS software to test if the control variables exhibited an underlying latent structure; ESRI ArcGIS software to clean, manage, and geocode data; and GeoDa Space software to estimate two-stage least squares spatially lagged regression models, which allowed us to control for spatial autocorrelation of dependent variables across neighboring block groups. To identify the spatial influence of neighboring census block groups on the dependent variable, we estimated spatial regression models with a first-order queen contiguity spatial weight matrix. We chose the contiguity spatial weight matrix because the units of analysis (i.e., census block groups) are arranged in a grid-like manner. We used first-order queen contiguity because we wanted to allow for equal influence of neighboring crime levels on our units of analysis. 
Spatially informed regression models are appropriate in this context because our dependent variables contain spatially referenced data. Spatial autocorrelation diagnostics indicated the violence levels in one unit of analysis were influenced by the processes from neighboring units, indicating spatial autocorrelation in the dependent variables. This is because spatially distributed data (e.g., locations of female violent victimization) generally exhibit patterned variation, or spatial autocorrelation, so that those data points closer together in space are more likely to have similar characteristics than those that further apart (Tobler, 1970). Once spatial autocorrelation was identified, we controlled for the effect of this nuisance on parameter estimates (Anselin, 1988; Anselin \& Bera, 1998) by adding a term for it (Rho) to the models.

We carried out four sets of analyses. The first two examined female violent victimization and female non-IPV violent victimization density. The last two examined male violent victimization and male non-IPV violent victimization density. Given theoretical expectations, all $p$ values were for one-tailed tests.

\section{Results}

Table 1 shows results of principal components analysis with one varimax rotation of the social disorganization variables. These results show control variables followed the social disorganization framework well, as evident in loadings and separations into each factor.

Table 1. Factor Loadings of Census Variables Into Four Factors.

\begin{tabular}{|l|l|l|l|l|}
\hline & Factor & & & \\
\hline & $\mathbf{1}$ & $\mathbf{2}$ & $\mathbf{3}$ & $\mathbf{4}$ \\
\hline Percent of adults with college education & .888 & -.270 & -.078 & -.101 \\
\hline Percent of professionals and managers & .854 & -.132 & -.245 & .058 \\
\hline among those in the civilian labor force & & & & \\
\hline Percent of families with incomes higher than & .685 & -.332 & -.034 & .428 \\
\hline US\$75,000 & & & & \\
\hline Percent female-headed families with children & -.508 & .422 & -.450 & -.196 \\
\hline Percent Hispanic or Latino & -.244 & .084 & .903 & -.014 \\
\hline Percent foreign-born & -.160 & -.011 & .898 & -.043 \\
\hline Percent African American & -.490 & .356 & -.703 & -.077 \\
\hline Percent of households on public assistance & -.112 & .884 & .006 & -.002 \\
\hline Percent unemployed & -.413 & .670 & -.129 & -.110 \\
\hline Percent living below poverty line & -.452 & .621 & .021 & -.383 \\
\hline Percent living in same house 1 year ago & -.054 & .074 & .070 & .890 \\
\hline Percent owner-occupied housing units & .184 & -.304 & -.079 & .838 \\
\hline
\end{tabular}

Tables 2 shows descriptive statistics for the untransformed variables. On average, Milwaukee block groups had 151 female violent victimizations per square mile and 106 female non-IPV violent victimizations per square mile, revealing most officially recorded female violent victimization is non-IPV victimization and demonstrating the need for more research on the topic. On average, block groups had 205 male violent victimizations per square mile and 181 male non-IPV violent victimizations per square mile. On average, block groups contained 15 onpremise and six off-premise alcohol outlets per square mile. We transformed the dependent, independent, and control variables to address their skewed distribution, and the descriptive statistics for the transformed variables are shown in Table 3 . As seen in Table 3, the transformation of these variables was successful in normalizing the distribution of the data.

Table 2. Descriptive Statistics for Untransformed Variables.

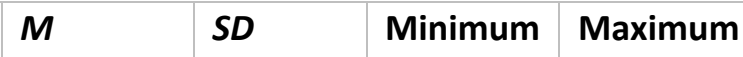




\begin{tabular}{|l|l|l|l|l|}
\hline Dependent variables & & & \\
\hline Female violent density & 151.30 & 153.96 & 0.00 & $1,054.66$ \\
\hline Female non-IPV density & 106.22 & 111.59 & 0.00 & 642.20 \\
\hline Male violent density & 205.01 & 209.88 & 0.00 & $1,028.65$ \\
\hline Male non-IPV density & 180.71 & 188.09 & 0.00 & $1,006.29$ \\
\hline Alcohol outlets & & & & \\
\hline On-premise density & 15.00 & 32.82 & 0.00 & 329.43 \\
\hline Off-premise density & 5.97 & 10.89 & 0.00 & 65.75 \\
\hline Social disorganization & & & & \\
\hline Concentrated affluence & 0.00 & 1.00 & -2.06 & 3.40 \\
\hline Concentrated disadvantage & 0.00 & 1.00 & -3.26 & 4.91 \\
\hline Cultural heterogeneity & 0.00 & 1.00 & -1.48 & 3.15 \\
\hline Residential stability & 0.00 & 1.00 & -4.03 & 2.13 \\
\hline Control variables & & & & \\
\hline Population density & $10,476.20$ & $6,662.68$ & 0.00 & $53,025.00$ \\
\hline Percent vacant housing units & 10.14 & 6.04 & 0.00 & 34.67 \\
\hline
\end{tabular}

Note. IPV = intimate partner violence.

Table 3. Descriptive Statistics for Transformed Variables.

\begin{tabular}{|l|l|l|l|l|}
\hline & M & SD & Minimum & Maximum \\
\hline Dependent variables & & & & \\
\hline Female violent density & 10.51 & 6.39 & 0.00 & 32.48 \\
\hline Female non-IPV density & 8.65 & 5.60 & 0.00 & 25.34 \\
\hline Male violent density & 12.17 & 7.56 & 0.00 & 32.07 \\
\hline Male non-IPV density & 11.36 & 7.19 & 0.00 & 31.72 \\
\hline Alcohol outlets & & & & \\
\hline On-premise density & 0.65 & 0.70 & 0.00 & 2.52 \\
\hline Off-premise density & 0.41 & 0.58 & 0.00 & 1.82 \\
\hline Social disorganization & & & & \\
\hline Concentrated affluence & 0.46 & 0.14 & 0.00 & 0.81 \\
\hline Concentrated disadvantage & 0.62 & 0.10 & 0.00 & 0.96 \\
\hline Cultural heterogeneity & 0.36 & 0.16 & 0.00 & 0.75 \\
\hline Residential stability & 0.47 & 0.14 & 0.00 & 0.85 \\
\hline Control variables & & & & \\
\hline Population density & 97.57 & 30.96 & 0.00 & 230.27 \\
\hline Percent vacant housing units & 3.05 & 0.91 & 0.00 & 5.89 \\
\hline Note. IPV = Intimate partner vion & & & & \\
\hline
\end{tabular}

Note. IPV = intimate partner violence.

Table 4 shows results of two spatially lagged regression models. Model 1 shows results for overall female violent victimization density regressed on alcohol outlet types net of controls. Model 2 shows results for female non-IPV violent victimization density regressed on alcohol outlet types net of controls. Results of Model 1 show female violent victimization density was not associated with on-premise alcohol outlets $(p=.09)$, while the association with off-premise outlets was significant $(p=.03)$. The variables in this model explained $79 \%$ of the variance in female violent victimization density. The multicollinearity condition number suggested multicollinearity was not a problem and that the inclusion of the spatial lag term (Rho) removed any remaining spatial autocorrelation in the model residuals (Anselin-Kelejian test, $p=.24$ ). Model 2 showed female non-IPV violent victimization density was associated with on-premise $(p=.01)$ and off-premise $(p=.03)$ outlet density. While the spatial autoregressive parameter (Rho) for female non-IPV violent victimization density was associated with female non-IPV violent victimization density $(p=.00)$, its inclusion did not remove all spatial autocorrelation in model 
residuals (Anselin-Kelejian test, $p=.02$ ). These variables explained $75 \%$ of the variance in the female non-IPV violent victimization density and multicollinearity was not a problem.

Table 4. Spatial Lag Regression for Female Violent Victimization Density and Female Non-IPV Violent Victimization Density Regressed on Alcohol Outlet Types, Social Disorganization, and Control Variables for Milwaukee Block Groups ( $=572$ ).

\begin{tabular}{|c|c|c|c|c|c|c|}
\hline & $\begin{array}{l}\text { Model 1: Female } \\
\text { Violent Victimization }\end{array}$ & & & $\begin{array}{l}\text { Model 2: Female Non- } \\
\text { IPV Violent } \\
\text { Victimization }\end{array}$ & & \\
\hline & b & SE & $\mathbf{p}$ & b & SE & $p$ \\
\hline On-premise & 0.28 & 0.21 & .09 & 0.52 & 0.20 & .01 \\
\hline Off-premise & 0.45 & 0.24 & .03 & 0.44 & 0.23 & .03 \\
\hline Concentrated affluence & -7.85 & 1.15 & .00 & -5.11 & 1.07 & .00 \\
\hline $\begin{array}{l}\text { Concentrated } \\
\text { disadvantage }\end{array}$ & 7.21 & 1.64 & .00 & 5.39 & 1.56 & .00 \\
\hline Cultural heterogeneity & -6.47 & 0.97 & .00 & -5.40 & 0.94 & .00 \\
\hline Residential stability & 1.52 & 1.02 & .07 & 0.83 & 0.98 & .20 \\
\hline Population density & 0.06 & 0.01 & .00 & 0.05 & 0.01 & .00 \\
\hline $\begin{array}{l}\text { Percent vacant housing } \\
\text { units }\end{array}$ & 0.91 & 0.21 & .00 & 0.67 & 0.20 & .00 \\
\hline $\begin{array}{l}\text { Rho female violent } \\
\text { victimization density }\end{array}$ & 0.51 & 0.05 & .00 & - & - & - \\
\hline $\begin{array}{l}\text { Rho female non-IPV } \\
\text { violent victimization } \\
\text { density }\end{array}$ & - & - & - & 0.58 & 0.06 & .00 \\
\hline Constant & -3.01 & 1.02 & .00 & -2.75 & 0.98 & .00 \\
\hline Pseudo- $R 2$ & & .79 & & & .75 & \\
\hline $\begin{array}{l}\text { Multicollinearity condition } \\
\text { number }\end{array}$ & & 27.81 & & & 27.81 & \\
\hline Anselin-Kelejian test & & $\begin{array}{l}1.40(p \\
=.24)\end{array}$ & & & $\begin{array}{l}5.45(p \\
=.02)\end{array}$ & \\
\hline
\end{tabular}

Note. Given theoretical expectations, all $p$ values are for one-tailed tests. IPV = intimate partner violence.

We estimated relationships for males to determine whether these associations were specific to female victimization. Table 5 shows results of two spatially lagged regression models. Model 3 shows results for overall male violent victimization density regressed on alcohol outlet types net of controls. Model 4 shows results for male non-IPV violent victimization density. Model 3 shows male violent victimization was positively associated with on-premise $(p=.01)$ and off-premise $(p<.01)$ alcohol outlet density. The spatial autoregressive parameter (Rho) for overall male violent victimization density was positively associated with male violent victimization density, though the inclusion of this term did not remove all spatial autocorrelation in model residuals (AnselinKelejian test, $p=.01$ ). These variables explained $82 \%$ of the variance in overall male violent victimization density, and the multicollinearity condition number suggests multicollinearity was not a problem in this model. Results for Model 4 show on-premise alcohol outlet density and off-premise alcohol outlet density were positively associated with male non-IPV violent victimization ( $p<.01$ for both). The spatial autoregressive parameter (Rho) was a significant contributor to the model $(p=.00)$, but it did not remove all of the remaining spatial dependence in the model residuals (Anselin-Kelejian test, $p=.00$ ). These variables explained $81 \%$ of variance in the male non-IPV violent victimization density, and multicollinearity condition number test statistic suggested that multicollinearity was not a problem. 
Table 5. Spatial Lag Regression for Male Violent Victimization Density and Male Non-IPV Violent Victimization Density Regressed on Alcohol Outlet Types, Social Disorganization, and Control Variables for Milwaukee Block Groups $(N=572)$.

\begin{tabular}{|c|c|c|c|c|c|c|}
\hline & $\begin{array}{l}\text { Model 3: Male } \\
\text { Violent Victimization }\end{array}$ & & & $\begin{array}{l}\text { Model 4: Male Non- } \\
\text { IPV Victimization }\end{array}$ & & \\
\hline & $b$ & $S E$ & $p$ & $b$ & $S E$ & $p$ \\
\hline On-premise & 0.65 & 0.23 & .01 & 0.64 & 0.23 & .00 \\
\hline Off-premise & 1.46 & 0.26 & .00 & 1.43 & 0.25 & .00 \\
\hline Concentrated affluence & -8.47 & 1.26 & .00 & -7.63 & 1.22 & .00 \\
\hline Concentrated disadvantage & 4.33 & 1.82 & .01 & 3.96 & 1.78 & .02 \\
\hline Cultural heterogeneity & -5.21 & 1.00 & .00 & -5.05 & 0.98 & .00 \\
\hline Residential stability & 0.38 & 1.13 & .37 & 0.53 & 1.11 & .32 \\
\hline Population density & 0.06 & 0.01 & .00 & 0.06 & 0.01 & .00 \\
\hline $\begin{array}{l}\text { Percent vacant housing } \\
\text { units }\end{array}$ & 0.64 & 0.23 & .01 & 0.57 & 0.22 & .01 \\
\hline $\begin{array}{l}\text { Rho male violent } \\
\text { victimization density }\end{array}$ & 0.63 & 0.05 & .00 & - & - & - \\
\hline $\begin{array}{l}\text { Rho male non-IPV violent } \\
\text { victimization density }\end{array}$ & - & - & - & 0.64 & 0.05 & .00 \\
\hline Constant & -1.26 & 1.15 & .14 & -1.27 & 1.13 & .13 \\
\hline Pseudo-R2 & & .82 & & & .81 & \\
\hline $\begin{array}{l}\text { Multicollinearity condition } \\
\text { number }\end{array}$ & & 27.81 & & & 27.81 & \\
\hline Anselin-Kelejian test & & $\begin{array}{l}7.17(p \\
=.01)\end{array}$ & & & $\begin{array}{l}9.21(p \\
=.00)\end{array}$ & \\
\hline
\end{tabular}

Note. Given theoretical expectations, all p values are for one-tailed tests. IPV = intimate partner violence.

Finally, to determine whether the positive effect of on- and off-premise density varied by gender, we tested for equality of regression coefficients between models using a $z$ test for the difference between slopes (Brame, Paternoster, Mazerolle, \& Piquero, 1998; Paternoster, Brame, Mazerolle, \& Piquero, 1998). The formula for this statistical test is

$$
Z=\frac{b_{1}-b_{2}}{\sqrt{S E b_{1}^{2}+S E b_{2}^{2}}}
$$

where $b_{1}$ is the slope for the female victimization, $b_{2}$ is the slope for the male victimization, $S E b_{1}$ is the standard error for the female victimization coefficient, and $S E b_{2}$ is the standard error for the male victimization coefficient.

This approach allows us to determine, in our two independent samples, the significance of the difference between female and male regression coefficients. While there are many tests for equality of regression coefficients (e.g., Clogg, Petkova, \& Haritou, 1995), some studies use tests with incorrect formulas leading the researchers to reach incorrect conclusions (see Brame et al., 1998, for summary of those studies). The test we use here not only correctly tests for these differences, but it is also very commonly used in criminological research.

We found the effect of on-premise outlets is similar for both genders: The difference between slopes for onpremise density was not statistically significant for female and male violent overall victimization $(p=.24)$, and female and male non-IPV violent victimization $(p=.70)$. We found the effect of off-premise was statistically 
different across genders: The difference between slopes for off-premise density was statistically significant for female and male violent victimization $(p=.00)$, and female and male non-IPV violent victimization $(p=.00)$. In other words, the formal tests of the differences suggest on-premise outlet density has the same effect on victimization for both genders, while the effect of off-premise outlet density is greater for male victimization (both overall violent victimization and non-IPV violent victimization) relative to female victimization.

\section{Discussion}

Of the 2,618,018 female violent victimizations reported in the 2014 National Crime Victimization Survey, 500,920 were between intimate partners (Truman \& Langton, 2015). There is little research on non-IPV female violent victimization generally and as it relates to alcohol and alcohol outlets specifically. Some studies found so few female-involved incidents they chose not to analyze them (Graham, 2000). Our study of Milwaukee provides several important initial findings. First, our findings indicate that in Milwaukee, off-premise, but not on-premise, alcohol outlet density is associated with overall female violent victimization. Second, both on-premise outlet density and off-premise outlet density are associated with female non-IPV violent victimization. Third, the findings show the association between outlet density and violent victimization is not restricted to females. Both on-premise outlet density and off-premise outlet density are associated with overall and non-IPV male victimization. Moreover, the effect of on-premise alcohol outlet density on overall and non-IPV violent victimization is similar across genders, though the effect of off-premise alcohol outlet density is smaller for female (both overall violent and non-IPV violent victimization) relative to male victimization.

Our findings are consistent with those of the few similar studies in this area. Our measures focused on outlet density given the lack of research of their effects on non-IPV female violent victimization. We did not operationalize specific theories that might explain the relationship between alcohol outlet density and female violent victimization rates (both overall and non-IPV), but we can draw on these theories to speculate about the reasons for our results. For example, our findings show indirect support for the adverse effects of availability theory, which argues greater alcohol accessibility stems from higher density of alcohol outlets and may lead to greater overall consumption in the area (Livingston et al., 2007). It may be the physical effects of intoxication lead to aggressive and risky behavior (Buddie \& Parks, 2003), resulting in victimization due to lowered inhibitions (Room et al., 2005) and reduced ability to defend oneself against an aggressor (Testa \& Parks, 1996).

Our results could also be explained by the idea that outlet density impacts routine activities. Different types of outlets may provide different environmental landscapes in which motivated offenders, vulnerable targets, and lack of suitable guardians converge in time and space (Cohen \& Felson, 1979). Some on-premise outlets may attract aggressive individuals, so an increase in the density of on-premise outlets could bring more aggressive individuals into an area (Leather \& Lawrence, 1995) that may act on opportunities for victimization. Density of alcohol outlets might also provide availability of targets for violent victimization (Homel \& Clark, 1994; Livingston et al., 2007), as the physical and pharmacological effects of excessive drinking can cause a person to be less aware of their surroundings and less attuned to dangerous situations, leading to greater victimization (Buddie \& Parks, 2003; Testa \& Parks, 1996). At on-premise outlets, intoxicated patrons leaving at closing time are more vulnerable to being a target of victimization, especially if they are leaving alone when guardianship over these outlets ceases (Homel \& Clark, 1994). Some routine activity theorists might argue on-premise outlets, especially bars and clubs, have bouncers, valet drivers, or other staff working outside the building who could provide greater surveillance over events occurring at or near their outlets. An area with several bars near each other would increase the number of people supervising the area. However, our findings show this is not the case. Some of these findings can be explained perhaps by the operating hours of these outlets. During operating hours, the on-premise outlets may be more likely to provide greater surveillance, but which ceases when it closes for the night. 
Alcohol purchased from off-premise outlets is generally consumed at home (Halonen et al., 2013), where vulnerable targets may experience victimization in absence of capable guardians (Cohen \& Felson, 1979). Moreover, lower priced alcohol beverages available at off-premise alcohol outlets may encourage private drinking relative to the price per unit of beverage consumed in on-premise outlets, so private drinking may result in more intoxicated and disinhibited offenders who may act on opportunities for victimization in the context of reduced guardianship (Cohen \& Felson, 1979). Greater consumption in the home could also lead to increased aggressive behavior that would typically not be displayed in public because of social norms that govern acceptable public behavior (Pernanen, 1993; Scribner et al., 1995). In addition, off-premise outlets do not usually staff someone to monitor the outside of the building, so aside from security cameras guardianship generally ends when a patron walks out of the door (Graham, Bernards, Osgood, Homel, \& Purcell, 2005).

We found no association between on-premise alcohol outlet density and overall female victimization, though the association exists between on-premise outlet density and male overall victimization. Previous research suggests intoxication and certain outlet characteristics may increase aggression, but these results typically focus on aggression between males (Leonard, Collins, \& Quigley, 2003). Concentration of outlets that serve intoxicated (Stockwell et al., 1993) and young patrons may create opportunities for increased rivalries among males for female attention (Buddie \& Parks, 2003) and vulnerability of females as targets for victimization (Homel \& Clark, 1994). A study by Krienert and Vandiver (2009) found assault victimization in bars is often an intragender phenomena, as men are more likely to assault men and women are more likely to assault women. Similarly, Lorraine, Quigley, and Leonard (2007) examined women's barroom experiences and found the opponent during the aggressive incident was more often another female than a male. Lorraine et al.'s (2007) respondents cited rowdy or obnoxious behavior and conflict over or about a romantic partner as precipitants to incidents with both male and female opponents, and cited sexual harassment as a precipitant to aggression in incidents involving male opponents.

These findings suggest intoxication in males might lead to more fights where both parties provoke the incident, whereas an increase in intoxication in females may not lead to the same aggression-provoking behavior and consequent victimization. The greater effect of off-premise density on male victimization may stem from patrons using these outlets as de facto taverns ( empty parking lot, or adjacent park. Both males and females who live in the neighborhoods surrounding the outlets could also be targeted for victimization, especially when they leave the bars, stores, and restaurants at closing time (Campbell et al., 2009). The differences between male and female victimization found in this study point to an important consideration that needs to be made in future studies of alcohol outlets and victimization. In particular, researchers should be cautious to avoid assuming the findings of studies of male victimization generalize to female victimization.

\section{Limitations}

We examined only alcohol outlet density and we did not control for other crime attractors and generators in the area like shopping precincts, sports stadiums, public transit exchanges, and insecure parking lots (Brantingham \& Brantingham, 1995) that could explain neighborhood crime patterns. Future studies should account for these factors to understand the unique impact of alcohol outlet density when the effect of other crime generators and attractors on female victimization is also included, though we note Grubesic, Pridemore, Williams, and PhilipTabb (2013) found the general association between alcohol outlet density and violence rates remained even when controlling for the presence of other commercial retailers generally and for risky retailers specifically (e.g., pawn shops, convenience stores, check cashing stores). Second, we did not examine the specific characteristics of outlets that could explain the association with female victimization. We discussed several possibilities in the "Literature Review" section and speculated further in the "Discussion" section. However, our goal was simply to explore if this association exists given the lack of prior research on non-IPV female violent victimization, and so we cannot make conclusions about the reasons for this association. Third, we did not examine whether and how the association between various outlet types with female victimization varies across time of day. It is possible 
that the effect of on-premise outlet density on female violent victimization is greatest at closing time when intoxicated and vulnerable bar patrons leave the premise in greater numbers, and future studies should test for this possibility. Last, while we did control for important indicators of social disorganization in our models, we did not examine how the association between outlet density and female victimization may be moderated by neighborhood social disorganization (Pridemore \& Grubesic, 2012). Perhaps alcohol outlets have the greatest effect on female victimization in socially disorganized neighborhoods because norms about intolerance of female victimization are not as salient as they are in socially organized neighborhoods (Browning, 2002) or because the impact of alcohol availability on violence is stronger in socially disorganized neighborhoods (Pridemore \& Grubesic, 2012).

\section{Future Research}

More research is needed to understand fully the link between alcohol outlet density and female violent victimization. For example, the differential effect size of off-premise density for male relative to female victimization suggests there may be different mechanisms at play for male and female victimization in relation to alcohol outlets. The role of sexual victimization for females in relation to alcohol outlet density should be further examined. This would allow for better evidence that could be used to inform harm reduction interventions or policies related to alcohol and alcohol outlet density. For example, because areas with higher outlet densities are associated with greater overall victimization as we showed here, policy initiatives that focus on restricting outlet density may have some impact on female victimization rates. In addition, while public service announcements targeting IPV already exist, the results of this study suggest public service announcements targeting non-IPV victimization-such as encouraging appropriate bystander interventions and supervision of friends' alcohol intake-may be warranted. Alcohol outlets could also implement policies that discourage victimization, like increasing guardianship in parking lots and alleyways around closing time or partnering with companies to ensure patrons have adequate transportation. Last, while our data do not allow us to examine the gender of the suspect, future studies should aim to study the role of suspect gender in genderspecific victimization, which could provide relevant information for violence intervention and prevention.

\section{Conclusion}

Violent victimization and offending is more prevalent for males than females (Lauritsen \& Heimer, 2008; Lauritsen, Heimer, \& Lynch, 2009), and most research on alcohol and violence considers only males or emphasizes males. The studies that do focus on alcohol and female violent victimization tend to focus on IPV (e.g., Waller et al., 2012), yet non-IPV victimization is a large proportion of all female violent victimization (Truman \& Langton, 2015). In this study, we focused on overall female victimization, compared overall female violent victimization with non-IPV violent female victimization, and tested to see if any associations are unique to females or are simply reflecting larger patterns of association found also among males. Our findings showed alcohol availability matters for female violent victimization even when controlling for neighborhood covariates of violence. On-premise alcohol outlets were positively associated with non-IPV female violent victimization, and off-premise alcohol outlets were positively associated with both overall and non-IPV female violent victimization. These findings suggest female violent victimization reflects the more general impact of alcohol outlet density on community violence, which is an important finding in itself given the emphasis thus far on males. Last, our findings showed that for our sample, the effect of on-premise outlets on both overall and nonIPV violent victimization is similar for both genders, but the effect of off-premise outlets is weaker for female relative to male victimization (for both overall and non-IPV violent victimization). Our results add to the understanding of the effects of alcohol outlet density on violence and female victimization generally, and they provide an important initial step in understanding alcohol outlets' impact on non-IPV female violent victimization. 


\section{Acknowledgements}

We thank Milwaukee Police Department Crime Analyst Daniel Polans and the Milwaukee Police Department for providing us the data for this research.

\section{Notes}

1. Alcohol outlets are retail establishments that are licensed for sale of alcoholic beverages. These include onpremise alcohol outlets, where consumption takes place while the patrons are visiting the premise (e.g., bars, restaurants, pubs, or taverns), and off-premise alcohol outlets (e.g., liquor, convenience, or grocery stores), where consumption takes place elsewhere.

\section{References}

Anselin, L. (1988). Spatial econometrics: Methods and models. Boston, MA: Kluwer Academic.

Anselin, L., \& Bera, A. K. (1998). Spatial dependence in linear regression models with an introduction to spatial econometrics. Statistics Textbooks and Monographs, 155, 237-290.

Babor, T., Caetano, R., Casswell, S., Edwards, G., Giesbrecht, N., Graham, K., . . Grube, J. W. (2010). Alcohol: No ordinary commodity: Research and public policy (2nd ed.). Oxford: Oxford University Press.

Benson, M. L., Fox, G. L., DeMaris, A., \& Van Wyk, J. (2003). Neighborhood disadvantage, individual economic distress and violence against women in intimate relationships. Journal of Quantitative Criminology, 19, 207-235.

Birckmayer, J. D., Holder, H. D., Yacoubian, G. S., \& Friend, K. B. (2004). A general causal model to guide alcohol, tobacco, and illicit drug prevention: Assessing the research evidence. Journal of Drug Education, 34, 121153.

Brame, R., Paternoster, R., Mazerolle, P., \& Piquero, A. (1998). Testing for the equality of maximum-likelihood regression coefficients between two independent equations. Journal of Quantitative Criminology, 14, 245-261.

Brantingham, P., \& Brantingham, P. (1995). Criminality of place. European Journal on Criminal Policy and Research, 3, 5-26.

Britt, H. R., Carlin, B. P., Toomey, T. L., \& Wagenaar, A. C. (2005). Neighborhood level spatial analysis of the relationship between alcohol outlet density and criminal violence. Environmental and Ecological Statistics, 12, 411-426.

Browning, C. R. (2002). The span of collective efficacy: Extending social disorganization theory to partner violence. Journal of Marriage and Family, 64, 833-850.

Buddie, A. M., \& Parks, K. A. (2003). The role of the bar context and social behaviors on women's risk for aggression. Journal of Interpersonal Violence, 18, 1378-1393.

Bursik, R. J. (1988). Social disorganization and theories of crime and delinquency: Problems and prospects. Criminology, 26, 519-552.

Campbell, C. A., Hahn, R. A., Elder, R., Brewer, R., Chattopadhyay, S., Fielding, J., . . Middleton, J. C. (2009). The effectiveness of limiting alcohol outlet density as a means of reducing excessive alcohol consumption and alcohol-related harms. American Journal of Preventive Medicine, 37, 556-569.

Clogg, C. C., Petkova, E., \& Haritou, A. (1995). Statistical methods for comparing regression coefficients between models. American Journal of Sociology, 100, 1261-1293.

Cohen, L. E., \& Felson, M. (1979). Social change and crime rate trends: A routine activity approach. American Sociological Review, 44, 588-608.

Cunradi, C. B. (2007). Drinking level, neighborhood social disorder, and mutual intimate partner violence. Alcoholism: Clinical \& Experimental Research, 31, 1012-1019.

Cunradi, C. B. (2009). Intimate partner violence among Hispanic men and women: The role of drinking, neighborhood disorder, and acculturation-related factors. Violence and Victims, 24, 83-97.

Cunradi, C. B. (2010). Neighborhoods, alcohol outlets and intimate partner violence: Addressing research gaps in explanatory mechanisms. International Journal of Environmental Research and Public Health, 7, 799-813. 
Cunradi, C. B., Caetano, R., Clark, C., \& Schafer, J. (2000). Neighborhood poverty as a predictor of intimate partner violence among White, Black, and Hispanic couples in the United States: A multilevel analysis. Annals of Epidemiology, 10, 297-308.

Cunradi, C. B., Mair, C., Ponicki, W., \& Remer, L. (2011). Alcohol outlets, neighborhood characteristics, and intimate partner violence: Ecological analysis of a California city. Journal of Urban Health, 88, 191-200.

Douglass, R. L., Wagenaar, A., \& Barkey, P. (1980). The relationship of changing alcohol availability to acute and chronic social and health problems. Currents in Alcoholism, 7, 104-125.

Duailibi, S., Ponicki, W., Grube, J., Pinsky, I., Laranjeira, R., \& Raw, M. (2007). The effect of restricting opening hours on alcohol-related violence. American Journal of Public Health, 97, 2276-2280.

Freisthler, B., Midanik, L. T., \& Gruenewald, P. J. (2004). Alcohol outlets and child physical abuse and neglect: Applying routine activities theory to the study of child maltreatment. Journal of Studies on Alcohol, 65(5), 586-592.

Graham, K. (2000). Preventive interventions for on-premise drinking: A promising but underresearched area of prevention. Contemporary Drug Problems, 27, 593-668.

Graham, K., Bernards, S., Osgood, D. W., Homel, R., \& Purcell, J. (2005). Guardians and handlers: The role of bar staff in preventing and managing aggression. Addiction, 100, 755-766.

Grannis, R. (1998). The importance of trivial streets: Residential streets and residential segregation. American Journal of Sociology, 103, 1530-1564.

Grubesic, T. H., Pridemore, W. A., Williams, D. A., \& Philip-Tabb, L. (2013). Alcohol outlet density and violence: The role of risky retailers and alcohol-related expenditures. Alcohol and Alcoholism, 48, 613-619.

Gruenewald, P. J., Freisthler, B., Remer, L., LaScala, E. A., \& Treno, A. (2006). Ecological models of alcohol outlets and violent assaults: Crime potentials and geospatial analysis. Addiction, 101, 666-677.

Halonen, J. I., Kivimaki, M., Virtanen, M., Pentti, J., Subramanian, S. V., Kawachi, I., \& Vahtera, J. (2013). Proximity of off-premise alcohol outlets and heavy alcohol consumption: A cohort study. Drug and Alcohol Dependence, 132, 295-300.

Heise, L. L. (1998). Violence against women: An integrated, ecological framework. Violence Against Women, 4, 262-290.

Homel, R., \& Clark, J. (1994). The prediction and prevention of violence in pubs and clubs. Crime Prevention Studies, 3, 1-46.

Krienert, J. L., \& Vandiver, D. M. (2009). Assaultive behavior in bars: A gendered comparison. Violence and Victims, 24, 232-247.

Lauritsen, J. L., \& Heimer, K. (2008). The gender gap in violent victimization, 1973-2004. Journal of Quantitative Criminology, 24, 125-147.

Lauritsen, J. L., Heimer, K., \& Lynch, J. P. (2009). Trends in the gender gap in violent offending: New evidence from the National Crime Victimization Survey. Criminology, 47, 361-399.

Leather, P., \& Lawrence, C. (1995). Perceiving pub violence: The symbolic influence of social and environmental factors. British Journal of Social Psychology, 34, 395-407.

Leonard, K. E., Collins, R. L., \& Quigley, B. M. (2003). Alcohol consumption and the occurrence and severity of aggression: An event-based analysis of male to male barroom violence. Aggressive Behavior, 29, 346365.

Livingston, M. (2011). A longitudinal analysis of alcohol outlet density and domestic violence. Addiction, 106, 919-925.

Livingston, M., Chikritzhs, T., \& Room, R. (2007). Changing the density of alcohol outlets to reduce alcoholrelated problems. Drug and Alcohol Review, 26, 557-566.

Lorraine, C. R., Quigley, B., \& Leonard, K. E. (2007). Women's physical aggression in bars: An event-based examination of precipitants and predictors of severity. Aggressive Behavior, 33, 304-313.

Nielsen, A. L., Hill, T. D., French, M. T., \& Hernandez, M. N. (2010). Racial/ethnic composition, social disorganization, and offsite alcohol availability in San Diego County, California. Social Science Research, 39, 165-175. 
O'Keefe, M., \& Treister, L. (1998). Victims of dating violence among high school students: Are the predictors different for males and females? Violence Against Women, 4, 195-223.

Parker, D. A., \& Wolz, M. W. (1979). Alcohol problems and the availability of alcohol. Alcohol Clinical Experimental Research, 3, 309-312.

Paternoster, R., Brame, R., Mazerolle, P., \& Piquero, A. (1998). Using the correct statistical test for the equality of regression coefficients. Criminology, 36, 859-866.

Pernanen, K. (1993). Research approaches in the study of alcohol-related violence. Alcohol Research \& Health, 17, 101-107.

Pridemore, W. A., \& Grubesic, T. (2013). Alcohol outlets and community levels of interpersonal violence: Spatial density, type of outlet, and seriousness of assault. Journal of Research in Crime and Delinquency, 50, 132-159.

Pridemore, W. A., \& Grubesic, T. H. (2012). A spatial analysis of the moderating effects of land use on the association between alcohol outlet density and violence in urban areas. Drug and Alcohol Review, 31, 385-393.

Pridemore, W. A., \& Snowden, A. J. (2009). Reduction in suicide mortality following a new national alcohol policy: An interrupted time series analysis of Slovenia. American Journal of Public Health, 99, 915-920.

Room, R., Babor, T., \& Rehm, J. (2005). Alcohol and public health. The Lancet, 365, 519-530.

Rowland, B., Toumbourou, J. W., Satyen, L., Tooley, G., Hall, J., Livingston, M., \& Williams, J. (2014). Associations between alcohol outlet densities and adolescent alcohol consumption: A study in Australian students. Addictive Behaviors, 39, 282-288.

Sampson, R. J. (1986). Crime in cities: The effects of formal and informal social control. Crime and Justice, 8, 271311.

Sampson, R. J., \& Groves, W. B. (1989). Community structure and crime: Testing social-disorganization theory. American Journal of Sociology, 94, 774-802.

Sampson, R. J., \& Raudenbush, S. W. (2004). Seeing disorder: Neighborhood stigma and the social construction of "broken windows". Social Psychology Quarterly, 67(4), 319-342.

Sampson, R. J., Raudenbush, S., \& Earls, F. (1997). Neighborhoods and violent crime: A multilevel study of collective efficacy. Science, 277, 918-924.

Sampson, R. J., \& Wooldredge, J. D. (1987). Linking the micro- and macro-level dimensions of lifestyle-routine activity and opportunity models of predatory victimization. Journal of Quantitative Criminology, 3, 371393.

Scribner, R. A., Cohen, D., Kaplan, S., \& Allen, S. H. (1999). Alcohol availability and homicide in New Orleans: Conceptual considerations for small area analysis of the effect of alcohol outlet density. Journal of Studies on Alcohol and Drugs, 60, 310-316.

Scribner, R. A., Mackinnon, D. P., \& Dwyer, J. H. (1995). The risk of assaultive violence and alcohol availability in Los Angeles County. American Journal of Public Health, 85, 335-340.

Shaw, C. R., \& McKay, H. D. (1942). Juvenile delinquency and urban areas. Chicago, IL: The University of Chicago Press. Snowden, A. J. (2015). The role of alcohol in violence: The individual, small group, community, and cultural level. Review of European Studies, 7, 394-406.

Snowden, A. J. (2016a). Alcohol outlet density and intimate partner violence in a non-metropolitan college town: Accounting for neighborhood characteristics and alcohol outlet types. Violence and Victims, 37, 111-123.

Snowden, A. J. (2016b). Neighborhood characteristics contribute to urban alcohol availability: Accounting for race/ethnicity and social disorganization. Journal of Ethnicity in Substance Abuse, 15, 346-366.

Snowden, A. J., \& Freiburger, T. (2015). Alcohol outlets, social disorganization, and robberies: Accounting for neighborhood characteristics and alcohol outlet types. Social Science Research, 51, 145-162.

Snowden, A. J., \& Pridemore, W. A. (2013). Alcohol and violence in a nonmetropolitan college town alcohol outlet density, outlet type, and assault. Journal of Drug Issues, 43, 357-373.

Stockwell, T., \& Gruenewald, P. (2001). Controls on the physical availability of alcohol. In N. Heather, T. J. Peters, \& T. Stockwell (Eds.), International handbook of alcohol dependence and problems (pp. 699-719). New York, NY: John Wiley. 
Stockwell, T., Lang, E., \& Rydon, P. (1993). High risk drinking settings: The association of serving and promotional practices with harmful drinking. Addiction, 88, 1519-1526.

Testa, M., \& Parks, K. A. (1996). The role of women's alcohol consumption in sexual victimization. Aggression and Violent Behavior, 1, 217-234.

Tobler, W. R. (1970). A computer movie simulating urban growth in the Detroit region. Economic Geography, 46, 234-240.

Truman, J. L., \& Langton, L. (2015). Criminal victimization, 2014 (NCJ 248973). Washington, DC: Bureau of Justice Statistics.

U.S. Census Bureau. (2014, January). State and county quickfacts. Retrieved from https://www.census.gov/quickfacts/

Waller, M. W., Iritani, B. J., Christ, S. L., Clark, H. K., Moracco, K. E., Halpern, C. T., \& Flewelling, R. L. (2012). Relationships among alcohol outlet density, alcohol use, and intimate partner violence victimization among young women in the United States. Journal of Interpersonal Violence, 27, 2062-2086.

Zhu, L., Gorman, D. M., \& Horel, S. (2004). Alcohol outlet density and violence: A geospatial analysis. Alcohol and Alcoholism, 39, 369-375.

\section{Author Biographies}

Aleksandra J. Snowden is an assistant professor in the Department of Social and Cultural Sciences at Marquette University. Her research interests include crime mapping and crime analysis, neighborhood characteristics, alcohol availability, violence, and spatial analytical methods.

Sara Hockin is a PhD student in the Department of Criminal Justice and Criminology at Georgia State University. Her research interests include program evaluation, systems change, and mental health care in the criminal justice system.

William Alex Pridemore is dean and professor in the School of Criminal Justice at the University at Albany-State University of New York. His research interests include the effects of social structure on homicide and suicide rates, alcohol epidemiology, and the sociology of health and illness. 